\title{
Feasibility Study of a Building-Integrated PV Manager to Power a Last-Mile Electric Vehicle Sharing System
}

\author{
Manuel Fuentes, ${ }^{1}$ Jesús Fraile-Ardanuy, ${ }^{2}$ José L. Risco-Martín, ${ }^{3}$ and José M. Moya ${ }^{4}$ \\ ${ }^{1}$ Renewable Energy Division, Energy Department, CIEMAT, Avda. Complutense 40, 28040 Madrid, Spain \\ ${ }^{2}$ ETSI Telecomunicación, Universidad Politécnica de Madrid, Avda. Complutense 30, 28040 Madrid, Spain \\ ${ }^{3}$ DACYA, Complutense University of Madrid, 28040 Madrid, Spain \\ ${ }^{4}$ Integrated Systems Laboratory, Center for Computational Simulation, Universidad Politécnica de Madrid, Avda. Complutense 30, \\ 28040 Madrid, Spain
}

Correspondence should be addressed to Manuel Fuentes; manuel.fuentes@ciemat.es

Received 30 October 2016; Accepted 21 February 2017; Published 26 April 2017

Academic Editor: Leonardo Sandrolini

Copyright (C) 2017 Manuel Fuentes et al. This is an open access article distributed under the Creative Commons Attribution License, which permits unrestricted use, distribution, and reproduction in any medium, provided the original work is properly cited.

\begin{abstract}
Transportation is one of the largest single sources of air pollution in urban areas. This paper analyzes a model of solar-powered vehicle sharing system using building-integrated photovoltaics (BIPV), resulting in a zero-emission and zero-energy mobility system for last-mile employee transportation. As a case study, an electric bicycle sharing system between a public transportation hub and a work center is modeled mathematically and optimized in order to minimize the number of pickup trips to satisfy the demand, while minimizing the total energy consumption of the system. The whole mobility system is fully powered with BIPVgenerated energy. Results show a positive energy balance in e-bike batteries and pickup vehicle batteries in the worst day of the year regarding solar radiation. Even in this worst-case scenario, we achieve reuse rates of 3.8 people per bike, using actual data. The proposed system manages PV energy using only the batteries from the electric vehicles, without requiring supportive energy storage devices. Energy requirements and PV generation have been analyzed in detail to ensure the feasibility of this approach.
\end{abstract}

\section{Introduction}

Most countries around the world are trying to reduce their total fossil-fuel consumption with the main objective of reducing their greenhouse gas (GHG) emissions, which are mainly responsible for global warming, climate change, and deterioration of air quality in cities [1]. Solar energy is an abundant source of renewable/sustainable energy, which has an enormous potential in reducing the footprint of the greenhouse gases [2]. The integration of photovoltaic systems into buildings (BIPV), as it is shown in Figure 1, is proving to be an increasingly endorsed solution, and this is the market segment with the greatest growth potential in the photovoltaic industry [3], replacing a significant amount of the electricity that would otherwise be generated by burning fossil fuels [4]; BIPV will gain increasing attention of the building energy efficiency market in the twenty-first century [5].

Nowadays, $50 \%$ of people are living in cities (reaching $69 \%$ in the European Union) and it is estimated that over
$60 \%$ of the total world's population will live in urban areas by 2030 [6], increasing the pressure in the urban environments. Bicycles can be used in urban areas to reduce air pollution, traffic congestion, noise emission, and energy consumption, allowing a personal healthier lifestyle [7]. For this reason, governments are promoting different initiatives to use bicycles as an alternative to private motor vehicles [8]. Different types of public bike sharing programs have emerged in many cities worldwide in recent years $[9,10]$. Bikes are distributed in different bike stations across the city, and users can pick up a bicycle from any docking station, returning it to any other one located within the network. These systems must be managed and maintained by operators, who are responsible for monitoring the stations and moving bicycles from the most loaded stations to the emptiest ones. Usually, these operators use a diesel-powered vehicle to deliver bikes between different bike stations as it is shown in Figure 2 . This management reduces problems that arise (a) when a particular user does not find a free bike when he/she wants to 

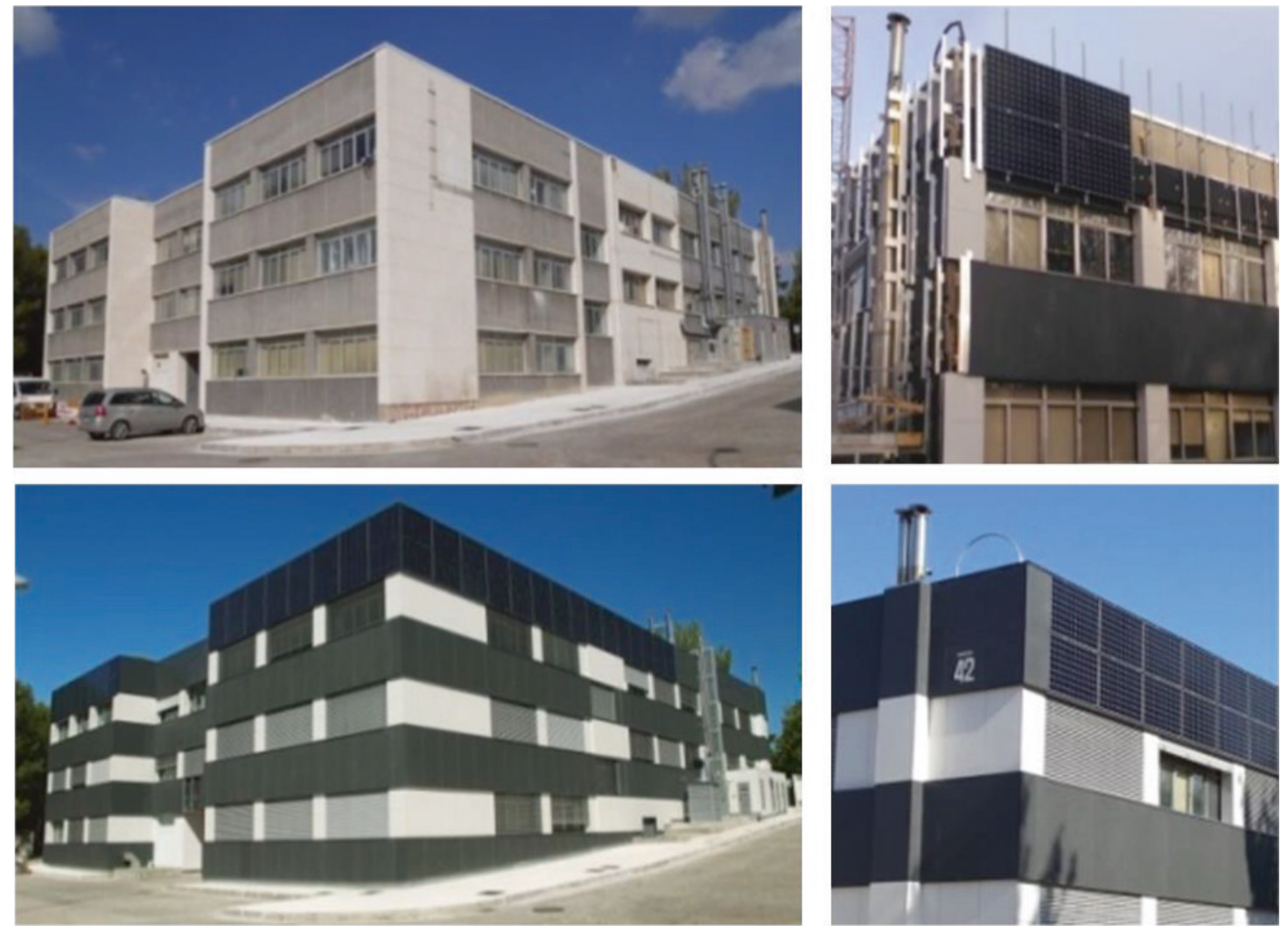

FIgURE 1: Southeast view of building 42 before and after rehabilitation of the shell. (BIPV) () CIEMAT.

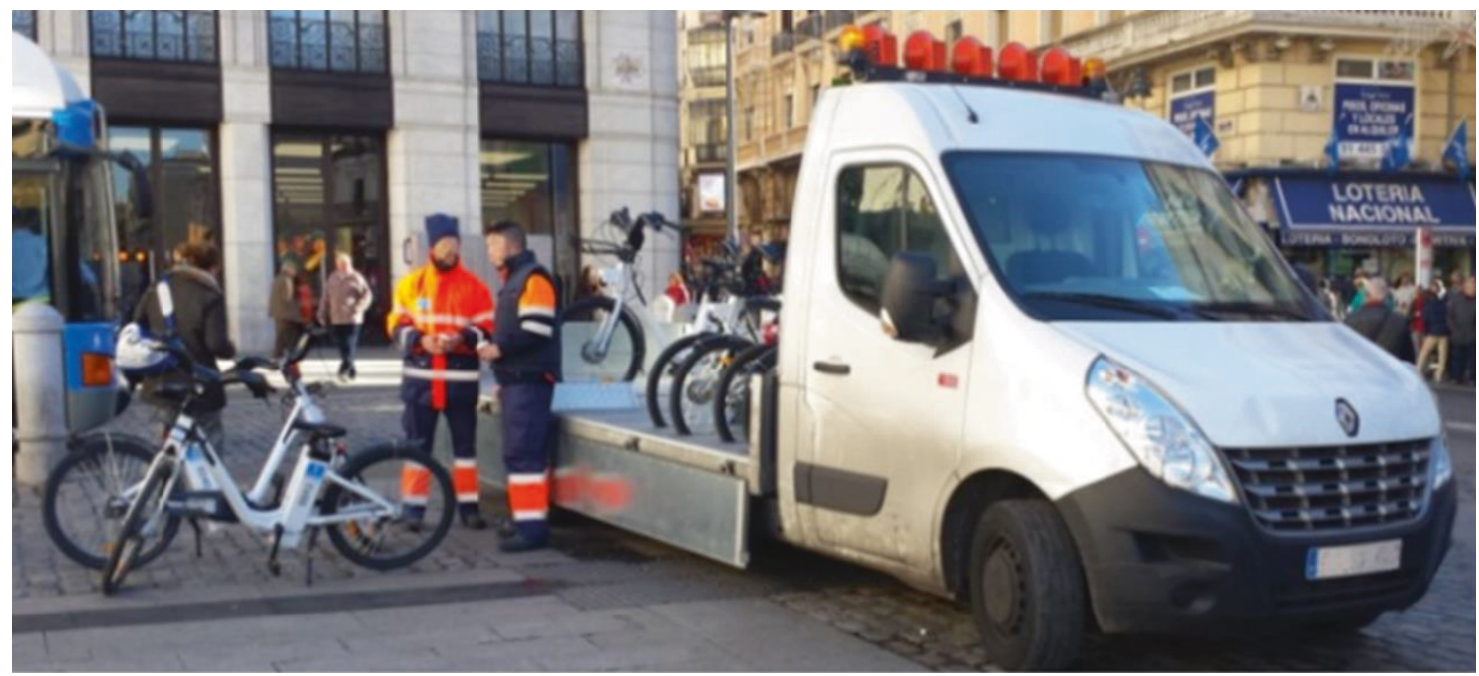

FIGURE 2: e-bike sharing system operators in Madrid (Spain).

use it in an empty station or (b) when he/she is not able to return the bike in a full station.

Bike sharing can be used in point-to-point trips, or it can be used combined with other transportation modes in cities, increasing the flexibility of public transport infrastructures. For example, one of the weakest points in a public transport system is the access (i.e., to reach public transport stations) and egress trips (i.e., from public transport stations to the final destination). Bikes can be used to cover these specific trips, reducing the door-to-door total travel time, making the combination of bicycle-public transport more competitive compared to private motor cars [11]. Cycling has also some disadvantages, like close passing traffic, exposure to weather conditions (heat, cold, rain, wind, etc.), difficulty to carry loads, and physical effort in hilly cities. Electric bicycles (e-bikes) are electric-powered-assisted bicycles that can 


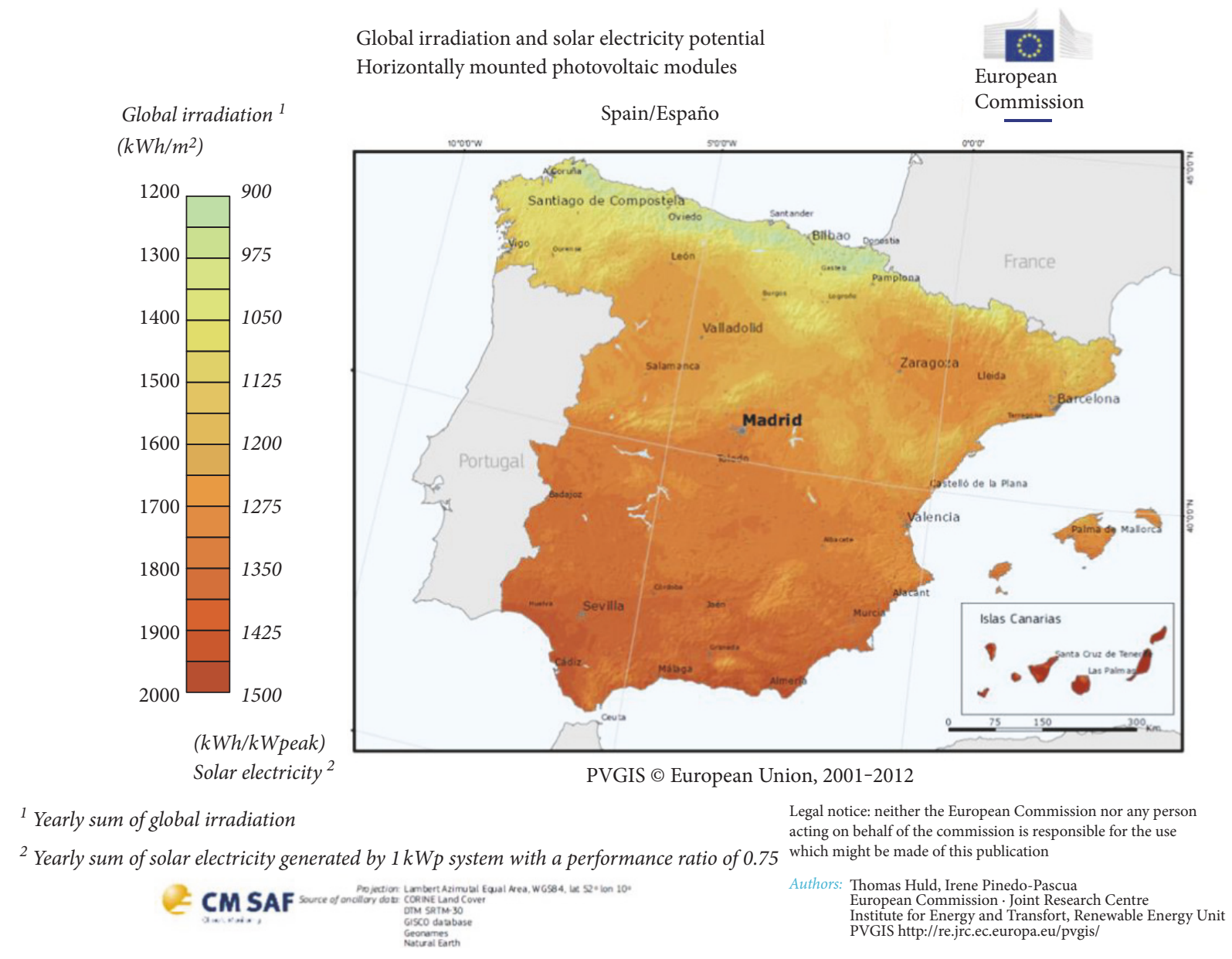

Figure 3: Global irradiation and solar electricity potential on horizontally mounted PV modules in Spain [16].

eliminate some of these problems, keeping all the benefits of traditional cycling. e-bike users can go further and faster with less fatigue than users on conventional ones, increasing the daily covered range [7]. This type of bicycle can be pedalled when the battery runs out.

Previous works demonstrated the feasibility and the economic relevance of introducing electric vehicles in lastmile urban logistics operations [12]. In this paper, we propose an e-bike sharing mobility system fully powered by BIPV-generated energy as a last-mile transportation solution, for people to go from public transportation hubs to their final destinations. This approach has been validated with real data obtained from a pilot implementation in a large work center in Spain.

Some e-bike sharing programs have emerged in different urban environments: that is, university campuses, such as the University of Tennessee (UTK), Knoxville Campus in the US [13] and in different European cities. In these e-bike sharing systems, batteries can be directly charged when e-bikes are parked or they can be swapped for fully charged ones in the docking stations. In both cases, the charging process extracts electric energy from the grid. The gap between PV power output and vehicle charging demand is highly variable [14]. In this paper, a system has been designed to adapt the daily BIPV generation curve of a work center to charge the batteries of the electric vehicles during working hours, which are also the period of maximum PV generation, to power the mobility system.

The remainder of this paper is organized as follows: Section 2 describes the case study, its characteristics, constraints, and models, including the estimation of PV generation and the energy demand of the mobility system; Section 3 describes and discusses the results of the energy-optimized system for this case study, resulting in a positive energy balance even in the worst day of the year; and finally, Section 4 summarizes the main conclusions of this work.

\section{Case Study: Last-Mile e-Bike Sharing System for CIEMAT}

As a case study, we analyze the feasibility of an electric bicycle sharing system between a public transportation hub and a research center in Madrid, Spain. This section provides a detailed analysis of this case, its constraints, and the estimation models for PV generation and total energy consumption of the mobility system.

2.1. CIEMAT Location. The Center for Advanced Research in Energy, Environment and Technology (Centro de Investigaciones Energéticas, Medioambientales y Tecnológicas- 
CIEMAT) is a public research institution located at the very end of the Moncloa Campus in Madrid (Spain) and occupying $71,000 \mathrm{~m}^{2}$. This integrated campus is shared with othereducational and research centers like Complutense University of Madrid, Technical University of Madrid, and some other partner institutions [15]. In Figure 3, spatial distribution of Spain cities is depicted against a backdrop of irradiation and PV theoretical energy.

The Moncloa Campus is situated in the west side of Madrid, covering an area of 2 square kilometers, and it is linked to the rest of the city public transport network by a single underground station called Ciudad Universitaria (line 6) [15], shown in Figure 4. The distance between CIEMAT offices and the nearest underground station is $1.1 \mathrm{~km}$ in straight and slightly sloping line.

2.2. Expected Solar Energy Generation. To estimate PV generation, we use the online calculator from Photovoltaic Geographical Information System (PVGIS) [16].

CIEMAT research centers are distributed in more than 70 different buildings in Moncloa Campus. Among them, CIEMAT building 42, which is the headquarters of the Renewable Energies Division, has recently installed a peak power of $27.2 \mathrm{kWp}$ of photovoltaic (PV) cells in the BIPV facades, occupying a total surface area of $176 \mathrm{~m}^{2}$ [3]. These $\mathrm{PV}$ modules are integrated in the upper areas of the east, south, and west facades with $90^{\circ}$ angle of inclination. There are 42 crystalline silicon modules installed in the east facade (13.7 kWp), 28 modules installed in the south facade $(8.5 \mathrm{kWp})$, and 16 modules installed in the west facade (4.9 kWp). This west PV subsystem is not considered in this work. The schematic of the BIPV modules installed in the south and east facades is shown in Figure 5.

In order to estimate the solar electricity production of this PV, in a similar way to [17], we need to first answer the following questions: What is the relation of irradiation values to the power load on a daily basis, and how should BIPV be integrated in the e-bike sharing power system?

Table 1 presents the average daily electricity production (Ed) and the average monthly electricity production (Em), also in $\mathrm{kWh}$, for the east and south facades. It is observed that the estimated annual energy generated by this PV system is 17.88 MWh/year, assuming an estimated loss due to temperature and low irradiance of $10.5 \%$, using local ambient temperature, an estimated loss due to angular reflectance effects of $5.3 \%$, and other losses (cables, inverters, etc.) of $14 \%$.

The worst months for PV generation, due to the low daily irradiance, are December and January [16] shown in Figure 6. The estimated solar energy generated by the PV panels located at CIEMAT building 42 during a single day in December is presented in Figure 7.

\subsection{Modeling and Predicting the Energy Consumption of the System}

2.3.1. Users' Daily Working Schedule. Most of the 1200 members of the CIEMAT staff at Moncloa Campus have a 40-hour working week, between 8:00 and 17:00, Monday to Friday, but they usually have a flexible work schedule. From

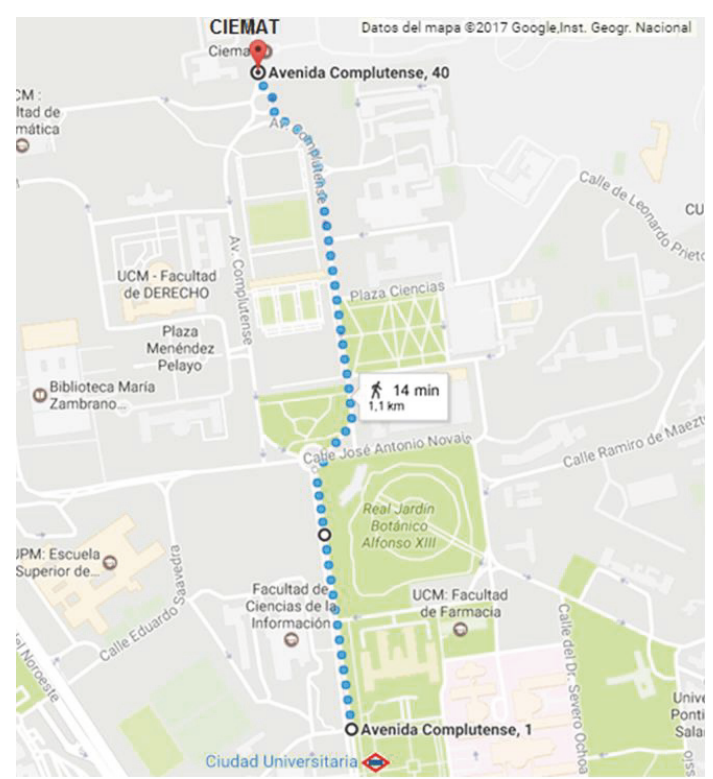

Figure 4: Moncloa Campus, Ciudad Universitaria underground station, and CIEMAT location.

different surveys [7], it has been pointed out that the rush hours are between from 7:00 to 10:00 in the morning and from 16:00 to 19:00 in the afternoon, and around 8\% of the staff (95 people) would be interested in participating in the proposed eco-mobility program.

Analyzing the underground timetable for line 6, the interval between two consecutive trains from 7:00 to 10:00 is 4 minutes. Taking into account the arrival time information extracted from those surveys, it is assumed that CIEMAT employees will arrive according to the probability density distribution shown in Figure 8, which resembles a Poisson distribution and matches the real observed mobility behavior. Most people arrive to work early (from 7:08 to $8: 20$ ), and then there is a long tail showing employees who arrive to work later. A similar probability density function is used for the afternoon return trips.

2.3.2. Evaluating the Optimal Number of e-Bikes and Electric Vehicles to Fulfill the Mobility Constraints. As aforementioned, the distance between the underground station and CIEMAT headquarters is $1.1 \mathrm{~km}$. e-bikes are initially locked in the bike station located outside the underground station. During the morning trips, subscribers will release the e-bikes from this dock station and will return it over an empty dock station located at the CIEMAT.

Assuming an average speed of $15-20 \mathrm{~km} /$ hour per e-bike [18], the average time to unlock the e-bike, ride, travel, and finally lock it back at the CIEMAT dock station is around 6 minutes.

As soon as the underground bike station empties and the CIEMAT bike station fills up, an electric pickup truck will tow back these e-bikes to the initial station. The estimated time for this shuttle and swapping operation is around 3.75 minutes (see Figure 9). It is assumed 4 minutes for the whole operation of this pickup electric vehicle (EV), 


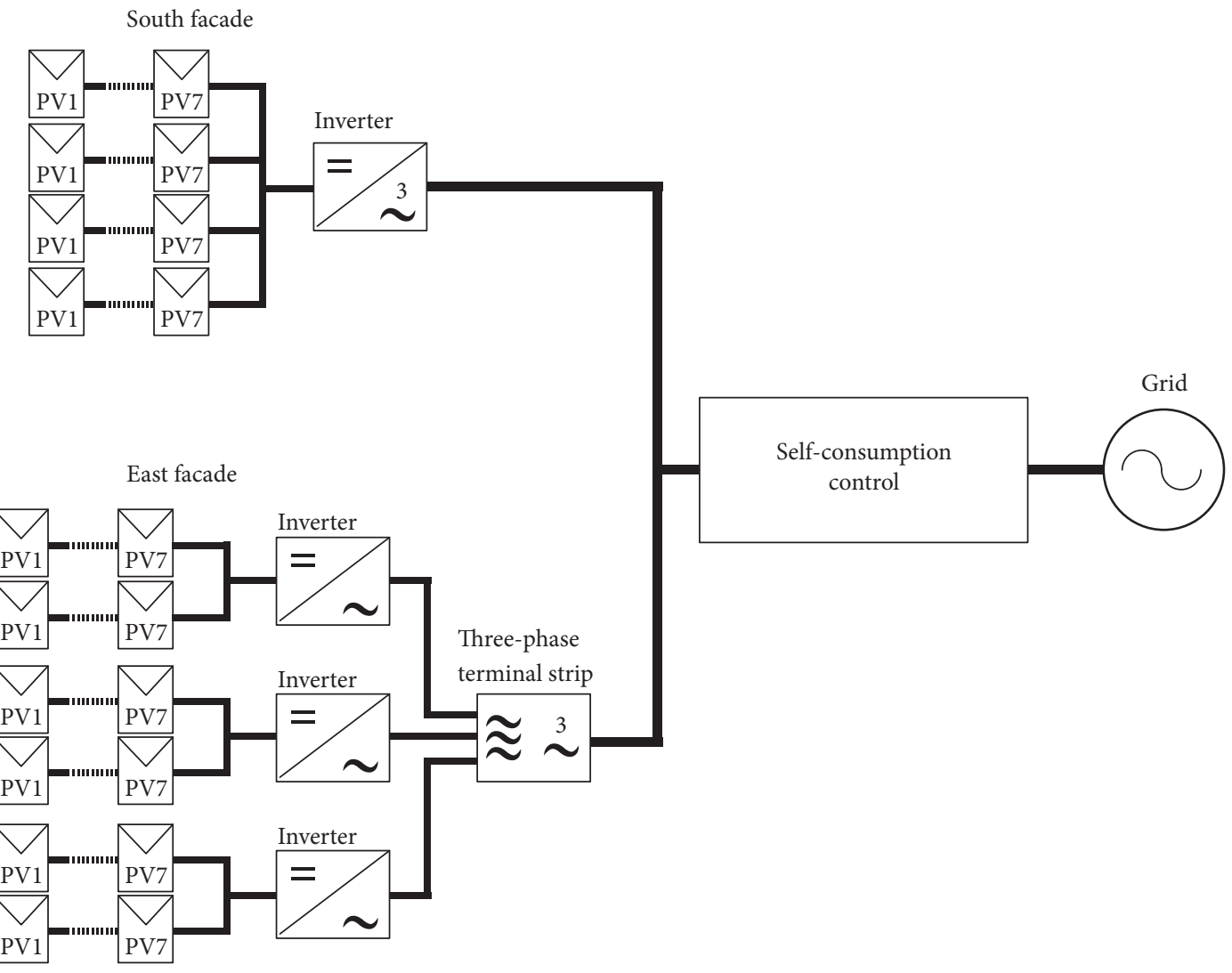

FIGURE 5: Schematic diagram of the BIPV modules installed in the south and the east facades.

TABLE 1: Average daily and monthly expected electricity production $(\mathrm{kWh})$ from the PV modules installed on the two considered facades, obtained from the PVGIS software [16].

\begin{tabular}{|c|c|c|c|c|}
\hline \multirow[b]{2}{*}{ Month } & \multicolumn{2}{|c|}{ East facade } & \multicolumn{2}{|c|}{ South facade } \\
\hline & Ed & Em & Ed & Em \\
\hline Jan & 24.10 & 748 & 13.80 & 429 \\
\hline Feb & 28.00 & 785 & 20.00 & 560 \\
\hline Mar & 27.90 & 864 & 28.30 & 878 \\
\hline Apr & 21.20 & 635 & 31.00 & 929 \\
\hline May & 16.40 & 507 & 34.70 & 1080 \\
\hline Jun & 14.00 & 419 & 37.70 & 1130 \\
\hline Jul & 15.00 & 466 & 38.40 & 1190 \\
\hline Aug & 20.60 & 639 & 35.00 & 1090 \\
\hline Sep & 26.50 & 795 & 29.10 & 872 \\
\hline Oct & 28.00 & 867 & 21.50 & 667 \\
\hline Nov & 24.90 & 748 & 14.80 & 445 \\
\hline Dec & 24.10 & 749 & 12.60 & 392 \\
\hline Yearly average & 22.50 & 685 & 26.50 & 805 \\
\hline Total for year & \multicolumn{2}{|c|}{8220} & \multicolumn{2}{|c|}{9660} \\
\hline
\end{tabular}

Total PV installation for a year 17880

including loading and unloading e-bikes, which is based on actual measurements. In a single hour, only $60 / 4=15$ trips can be performed by this EV towing the e-bikes between

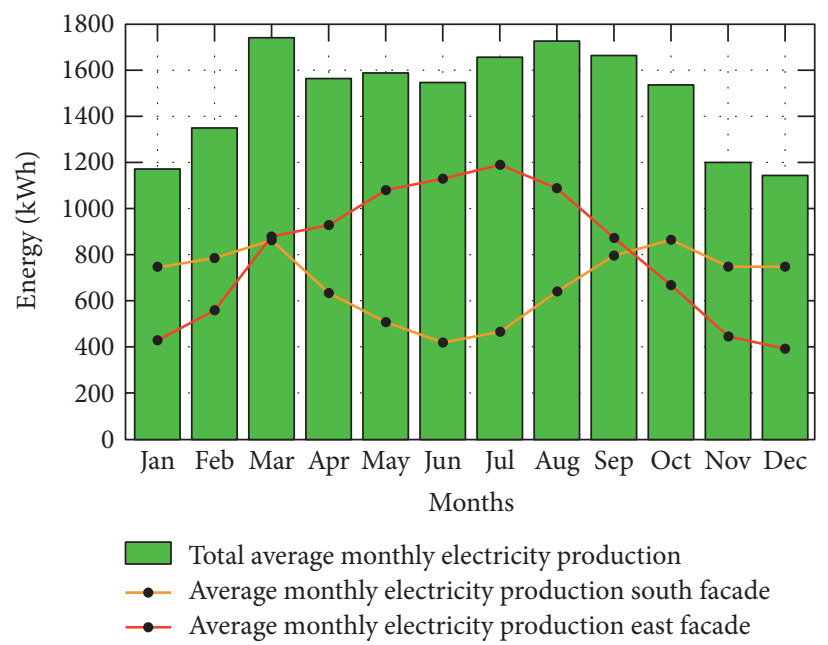

FIgURE 6: Average monthly expected electricity production.

these two locations. This is the upper-bound limiting factor of the whole e-bike sharing system.

2.3.3. Estimation of e-Bike Sharing System Energy Demand. (1) Estimation of e-Bike Energy Consumption. The electric motor used is a $250 \mathrm{~W}$ brushless synchronous motor embedded into the rear wheel hub. The main electric specifications of the e-bike are presented in Table 2. 


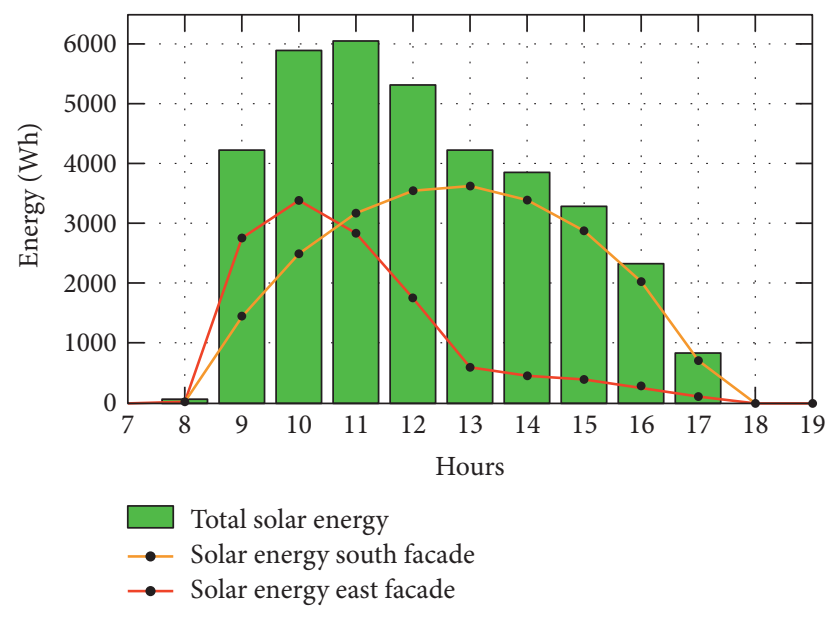

Figure 7: Estimated solar energy generated at December day.

To estimate the e-bike average consumption, two different tests were performed. Firstly, different users rode an e-bike during 3 months around the CIEMAT headquarters, measuring travelled distance, average vehicle speed, travel time, and energy consumed. From this data, energy consumption per kilometer was evaluated. Table 3 summarizes this information.

A second test was performed over the real route between the underground station and CIEMAT headquarters. Two different users, with very different weight $(122 \mathrm{~kg}$ versus $75 \mathrm{~kg}$ ), travelled across this route at the same time, riding two e-bikes. Table 4 shows the energy consumption in this situation. The energy consumption per kilometer and energy consumption per kilometer and kilogram were derived from this data. Taking into account these results, a conservative $7.7 \mathrm{Wh} / \mathrm{km}$ was used in this work.

(2) Estimation of the Towing Electric Vehicle. The EV considered in this analysis is the pickup vehicle Nissan eNV200 with the same electric propulsion system with Nissan Leaf. This car is $100 \%$ EV powered by AC synchronous motor $80 \mathrm{~kW}-280 \mathrm{Nm}$, with a $24 \mathrm{kWh}$ laminated lithium-ion battery. Its range is $170 \mathrm{~km}$ when tested according to the New European Driving Cycle (NEDC), which corresponds to $0.165 \mathrm{kWh} / \mathrm{km}$ [19]. According to different real field tests [20], the average real consumption for this vehicle in this study has been selected to $0.18 \mathrm{kWh} / \mathrm{km}$.

2.4. Determining the Mobility Requirements. The objective of the designed mobility system is to satisfy the demand of CIEMAT employees between the underground station and work site in the morning and afternoon, minimizing the number of trips performed by the pickup EV trailer, defined by (1).The optimization problem is defined as a mixed integer linear programming problem given by (1)-(9). Table 5 presents the optimization model parameters with their associated value ranges. Table 6 shows integer variables used in the optimization model with their associated limits. In order to clarify the notation, underground station will be labeled as $\mathrm{A}$, whereas the CIEMAT station will be labeled as B.

$$
\min \sum_{t}\left(\mathrm{dk}_{\mathrm{AB}}(t)+\mathrm{dk}_{\mathrm{BA}}(t)\right)
$$

subject to

$$
\begin{aligned}
& \mathrm{nb}_{\mathrm{A}}(t)= \mathrm{NB}_{\mathrm{A} 0}, \text { if } t \leq 0 \\
& \mathrm{nb}_{\mathrm{A}}(t)=0, \text { if } t>0, t \in \mathrm{BCTI} \\
& \mathrm{nb}_{\mathrm{A}}(t)= \mathrm{nb}_{\mathrm{A}}(t-1)-D_{\mathrm{AB}}(t)+D_{\mathrm{BA}}\left(t-\Delta T_{\mathrm{BA}} \mathrm{AEB}\right) \\
&-\mathrm{Cb}_{\mathrm{AB}}(t)+\mathrm{Cb}_{\mathrm{BA}}\left(t-\Delta T_{\mathrm{BA}}\right), \\
& \text { if } t>0, t \notin \mathrm{BCTI},
\end{aligned}
$$

$$
\begin{aligned}
\mathrm{nb}_{\mathrm{B}}(t)= & \mathrm{NB}_{\mathrm{B} 0}, \text { if } t \leq 0 \\
\mathrm{nb}_{\mathrm{B}}(t)= & \mathrm{NB}_{\mathrm{TOT}}, \text { if } t>0, t \in \mathrm{BCTI} \\
\mathrm{nb}_{\mathrm{B}}(t)= & \mathrm{nb}_{\mathrm{B}}(t-1)-D_{\mathrm{BA}}(t)+D_{\mathrm{AB}}\left(t-\Delta T_{\mathrm{AB}}{ }^{\mathrm{AEB}}\right) \\
& \left.-\mathrm{Cb}_{\mathrm{BA}}(t)+\mathrm{Cb}_{\mathrm{AB}}\left(t-\Delta T_{\mathrm{AB}}{ }^{\mathrm{K}}\right)\right), \\
& \text { if } t>0, t \notin \mathrm{BCTI},
\end{aligned}
$$

$$
\begin{aligned}
& \mathrm{nk}_{\mathrm{A}}(t)=\mathrm{NK}_{\mathrm{A} 0}, \text { if } t \leq 0 \\
& \mathrm{nk}_{\mathrm{A}}(t)=0, \text { if } t>0, t \in \mathrm{BCTI} \\
& \mathrm{nk}_{\mathrm{A}}(t)=\mathrm{nk}_{\mathrm{A}}(t-1)-\mathrm{dk}_{\mathrm{AB}}(t)+\mathrm{dk}_{\mathrm{BA}}\left(t-\Delta T_{\mathrm{BA}}{ }^{\mathrm{K}}\right), \\
& \quad \text { if } t>0, t \notin \mathrm{BCTI},
\end{aligned}
$$

$$
\begin{aligned}
& \mathrm{nk}_{\mathrm{B}}(t)=\mathrm{NK}_{\mathrm{B} 0}, \text { if } t \leq 0 \\
& \mathrm{nk}_{\mathrm{B}}(t)=\mathrm{NK}_{\mathrm{TOT}}, \text { if } t>0, t \in \mathrm{BCTI}, \\
& \mathrm{nk}_{\mathrm{B}}(t)=\mathrm{nk}_{\mathrm{B}}(t-1)-\mathrm{dk}_{\mathrm{BA}}(t)+\mathrm{dk}_{\mathrm{AB}}\left(t-\Delta T_{\mathrm{AB}}{ }^{\mathrm{K}}\right), \\
& \quad \text { if } t>0, t \notin \mathrm{BCTI},
\end{aligned}
$$

$$
\begin{aligned}
& \mathrm{Cb}_{\mathrm{AB}}(t)=0, \text { if } t \leq 0 \text { or } t \in \mathrm{BCTI} \\
& \mathrm{Cb}_{\mathrm{AB}}(t) \leq A_{\mathrm{EB}} \mathrm{CT} \cdot \mathrm{dk}_{\mathrm{AB}}(t), \text { if } t>0, t \notin \mathrm{BCTI}, \\
& \mathrm{Cb}_{\mathrm{BA}}(t)=0, \text { if } t \leq 0 \text { or } t \in \mathrm{BCTI} \\
& \mathrm{Cb}_{\mathrm{BA}}(t) \leq A_{\mathrm{EB}} \mathrm{CT} \cdot \mathrm{dk}_{\mathrm{BA}}(t), \text { if } t>0, t \notin \mathrm{BCTI},
\end{aligned}
$$

$$
\begin{aligned}
\mathrm{db}_{\mathrm{AB}}(t)= & 0, \text { if } t \leq 0 \text { or } t \in \mathrm{BCTI} \\
\mathrm{db}_{\mathrm{AB}}(t)= & \mathrm{db}_{\mathrm{AB}}(t-1)+D_{\mathrm{AB}}(t-1) \\
& -D_{\mathrm{AB}}\left(t-\Delta T_{\mathrm{AB}}^{\mathrm{AEB}}\right),
\end{aligned}
$$

if $t>0, t \notin \mathrm{BCTI}$,

$$
\begin{aligned}
\mathrm{db}_{\mathrm{BA}}(t)= & 0, \text { if } t \leq 0 \text { or } t \in \mathrm{BCTI} \\
\mathrm{db}_{\mathrm{BA}}(t)= & \mathrm{db}_{\mathrm{BA}}(t-1)+D_{\mathrm{BA}}(t-1) \\
& -D_{\mathrm{BA}}\left(t-\Delta T_{\mathrm{BA}}{ }^{\mathrm{AEB}}\right), \\
& \text { if } t>0, t \notin \mathrm{BCTI} .
\end{aligned}
$$

Equation (1) defines the objective function to be minimized by the optimization algorithm. This equation evaluates 


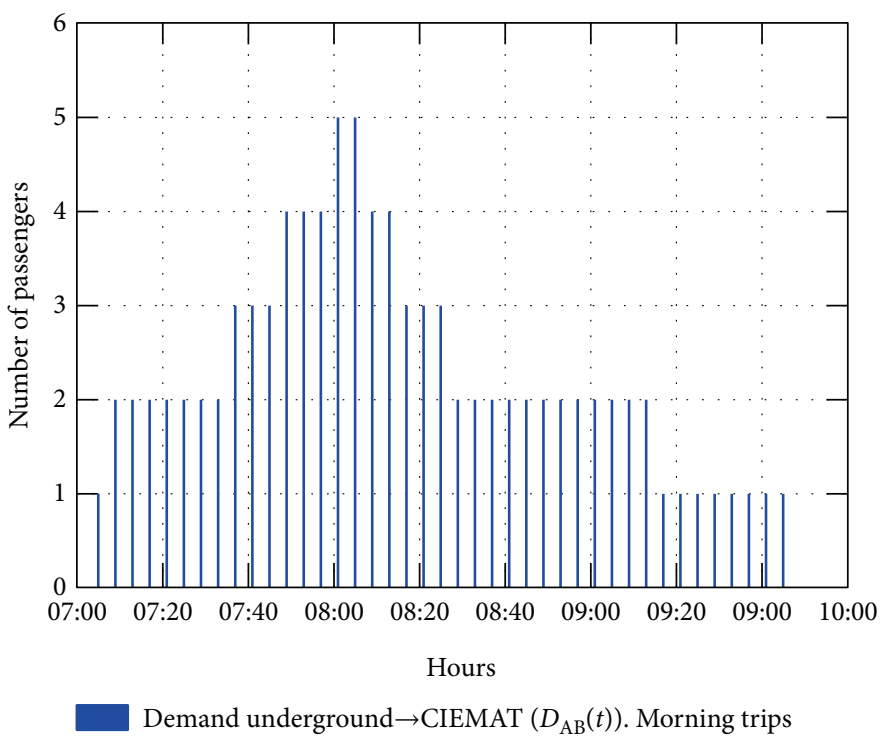

Figure 8: Temporal distribution of CIEMAT staff members' arrivals per time slot during the morning period.

the number of trips performed by the pickup EV between both nodes (from A to B) along the day at each time slot (given by $\left.\mathrm{dk}_{\mathrm{AB}}(t)+\mathrm{dk}_{\mathrm{BA}}(t)\right)$. Remember that these trips are done to maintain the balance of the e-bike fleet parked at each docking station. Energy required for e-bikes depends only on the demand, and there is no way to reduce it. The remaining energy requirements come from the pickup trips required to satisfy the demand with a certain number of e-bikes, which can be minimized.

Equations (2) and (3) define the general balance of the number of e-bikes in each docking station at each time slot. During the charging time interval (10:00 to 16:00), the e-bikes are charging in B. In normal operation, in (2), the number of e-bikes at $\mathrm{A}$ at time slot $t$, denoted by $\mathrm{nb}_{\mathrm{A}}(t)$, is equal to the number of e-bikes parked at this station in the previous time slot, $\mathrm{nb}_{\mathrm{A}}(t-1)$, minus the number of e-bikes used by the demand to travel from the $\mathrm{A}$ to $\mathrm{B}$, denoted by $D_{\mathrm{AB}}(t)$, adding the number of e-bikes which departed from $\mathrm{B}$ previously, at $t=t-\Delta T_{\mathrm{BA}}{ }^{\mathrm{AEB}}$, denoted by $D_{\mathrm{BA}}\left(t-\Delta T_{\mathrm{BA}}{ }^{\mathrm{AEB}}\right)$, minus the number of e-bikes transported by the pickup EV from $\mathrm{A}$ to $\mathrm{B}$, denoted by $\mathrm{Cb}_{\mathrm{AB}}(t)$, and adding the number of e-bikes transported by the pickup EV from the B to the A, which departed at $t=t-\Delta T_{\mathrm{BA}} \mathrm{K}$.

During the morning, the employees' demand to travel, using their e-bikes from CIEMAT to the underground station, $D_{\mathrm{BA}}(t)$, will be zero, and also the number of e-bikes transported by the pickup trailer from the underground dock station to CIEMAT one, $\mathrm{Cb}_{\mathrm{AB}}(t)$, will be zero. During the afternoon trips, this behavior is reversed; therefore, $D_{\mathrm{AB}}(t)$ and $\mathrm{Cb}_{\mathrm{BA}}(t)$ will be zero. The same procedure has been applied in (3).

Equations (4) and (5) model the behavior of the pickup $\mathrm{EV}$ in each docking station at each time slot.

Restrictions (6) and (7) limit the maximum number of e-bikes that can be transported in each pickup-EV trip from A to $B$ and reversed. Equations (8) and (9) present the continuity equations for each e-bike movement.
IBM ILOG CPLEX Optimization Studio v. 12.5.1.0 was used for solving the defined optimization problem, and MATLAB ${ }^{\circledR}$ was later used for analyzing and plotting the results.

\section{Results and Discussion}

3.1. Mobility. It is assumed that a single pickup EV was used in this system. The optimal number of e-bikes in this fleet is then evaluated running the optimization model and checking its convergence. If a feasible solution is not obtained, the number of e-bikes is increased in one until convergence is reached.

With this procedure, the minimum number of e-bikes in the fleet that can fulfill the mobility requirements was fixed to 25 , as it is presented in Table 5 .

Once the minimum number of pickup EV and e-bikes were set in the sharing system, the optimization algorithm was run to determine the minimum number of trips from pickup EV required to balance the e-bike fleet. This value was 28 during each demand period (28 in the morning trips and 28 more in the afternoon).

The optimization model also determines the optimal moment to transport the e-bikes from CIEMAT dock station to the underground station, avoiding e-bike scarcity in this last dock station, and the exact number of bikes moved in each trips (it is an integer variable between 1 and 5). It is important to notice that at the end of the morning, all e-bikes and the pickup EV are located at the CIEMAT in order to be recharged before the afternoon trips.

3.2. Energy Demanded by the e-Bike Sharing System. In a similar way, controlling charging and discharging of lead-acid batteries is critical to extend the lifetime of microgrid systems [21]; our work has taken into account the optimum management of the state of charge (SOC) for lithium-polymer 

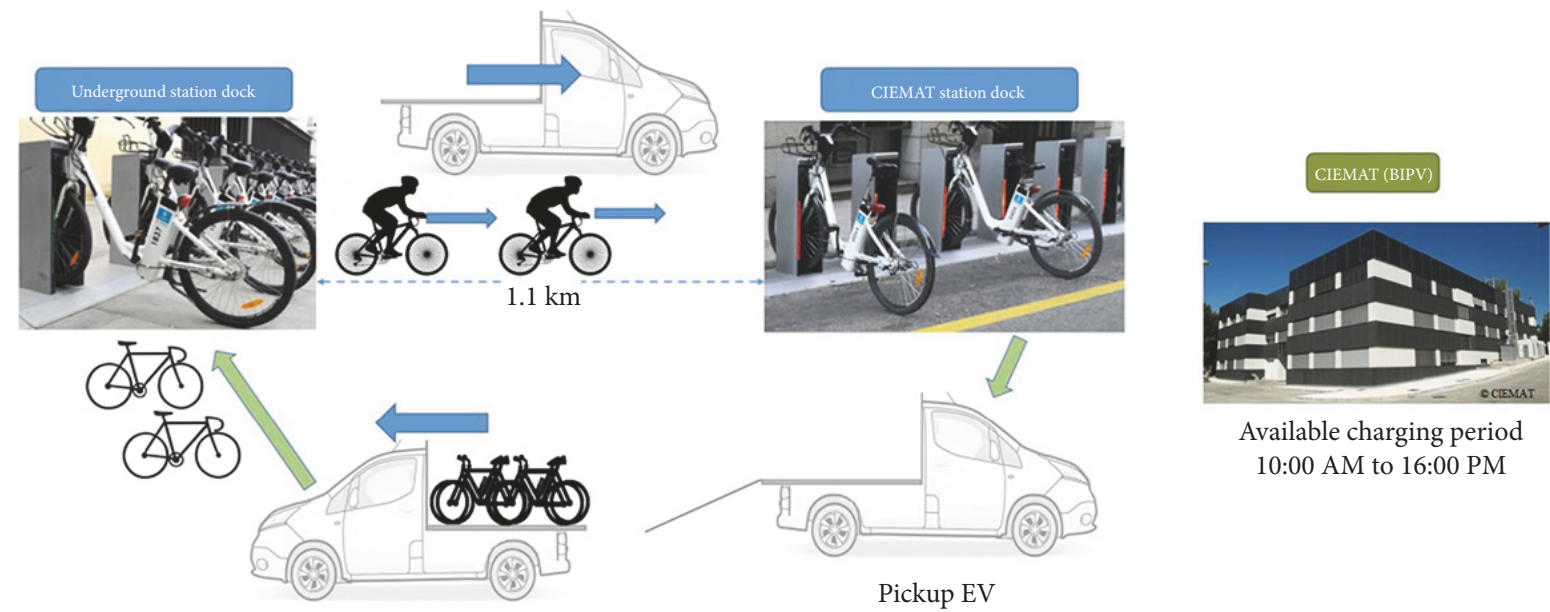

FIGURE 9: e-bike sharing system mobility description.

TABLE 2: e-bike specifications.

\begin{tabular}{lcccccc}
\hline Battery tech. & Nominal voltage & Nominal capacity & Weight & Motor & Nominal power & Bike weight \\
\hline Li-ion polymer & $36 \mathrm{~V}$ & $360 \mathrm{Wh}$ & $4.6 \mathrm{~kg}$ & Brushless & $250 \mathrm{~W}$ & $20.4 \mathrm{~kg}$ \\
\hline
\end{tabular}

TABLE 3: Electric consumption data from CIEMAT headquarters tests.

\begin{tabular}{lcccc}
\hline Distance & Time & $\begin{array}{c}\text { Average } \\
\text { speed }\end{array}$ & $\begin{array}{c}\text { Energy } \\
\text { consumed }\end{array}$ & Consumption \\
\hline $1450 \mathrm{~km}$ & $108.5 \mathrm{~h}$ & $13.6 \mathrm{~km} / \mathrm{h}$ & $11.62 \mathrm{kWh}$ & $8.01 \mathrm{Wh} / \mathrm{km}$ \\
\hline
\end{tabular}

batteries of the electric bicycles and lithium-ion batteries of the electric pickup vehicles, with the aim of extending the system lifetime.

From the previous mobility analysis, it is observed that during the morning period (from 7:00 to 10:00), the total number of e-bike trips is 95 . The energy required per bike during this period is $8.459 \mathrm{Wh} / \mathrm{e}-\mathrm{bike}$, and the energy demanded by the e-bike fleet during the morning period will be $803.605 \mathrm{Wh}$. The total energy demanded by the e-bike fleet for the full day will be 1607.21 Wh.

The total number of trips by pick up EV trailer during the morning period is 28 , consuming $5.544 \mathrm{kWh}$. The total energy demanded by the EV trailer for the full day will be $11.088 \mathrm{kWh}$, and the total amount of energy required by the proposed e-bike sharing system (e-bikes plus EV trailer) will be $12.7 \mathrm{kWh}$ /day. Table 7 summarizes all energy mobility requirement of the proposed system.

There is a charging station located outside CIEMAT building 42 , which is connected to the PV panels through three $10 \mathrm{~kW}$ single-phase MPPT inverters. This charging station is composed by an AC level 2 charging point, which operates at $3.7 \mathrm{~kW}(230 \mathrm{~V} / 240 \mathrm{~V}-16 \mathrm{~A})$ to charge the pickup EV trailer and 25 Schuko plugs type $\mathrm{F}$ (also known as CEE $7 / 4$ ) protected by 5 single-pole $6 \mathrm{~A} 230 / 240 \mathrm{~V}, 50 \mathrm{~Hz}$, circuit breaker to charge the e-bikes.
The complete e-bike sharing system will be recharged during the midday period (10:00 to 16:00), when all CIEMAT employees are working and there is no demand for trips. At the beginning of the day, all e-bikes are parked at the underground docking station and the EV trailer is empty and parked at CIEMAT. It is assumed that the initial capacity of the e-bikes is $1 \mathrm{kWh}$ ( $11.11 \%$ of the total e-bike capacity), and the initial capacity of the EV trailer is $8 \mathrm{kWh}(33.33 \%$ of the EV trailer battery capacity). The solar resource is not available early in the morning; therefore, it is necessary to have energy in the batteries of the pickup and e-bikes to be able to perform the first morning trips. With these assumptions, we prove that, even in the worst day of the year, the remaining energy at the end of the day is even higher.

As soon as the employees start to arrive in the morning, they pick up an e-bike from the docking station, returning it to the EV trailer in the CIEMAT headquarters. When the EV trailer is full, this vehicle will carry back the e-bikes to the docking station located near the metro station. During these trips, all vehicles involved in this sharing system (EV trailer and e-bikes) will spend energy. Figure 10 shows the e-bike sharing system hourly energy consumption for a sample day.

The worst months for PV generation, due to the daily low irradiance are December and January [16]. The estimated solar energy generated by the PV panels located at CIEMAT building 42 during a single day in December is presented in Figure 11. In this figure, negative blue bars represent the total sharing system hourly energy consumption and the positive estimated solar generation is shown in red and yellow bars. e-bike sharing system will be recharged during the remainder period between 10:00 and 16:00 (highlighted with yellow bars). 
TABLE 4: Electric consumption from two different users over the same specific route.

\begin{tabular}{lccc}
\hline & Distance & Time & Average speed \\
\hline & $1.1 \mathrm{~km}$ & $5 \mathrm{~min}$ & $15 \mathrm{~km} / \mathrm{h}$ \\
\hline User $122 \mathrm{~kg}$ & Energy consumed & Energy consumed $/ \mathrm{km}$ & Energy consumed $/ \mathrm{km} / \mathrm{kg}$ \\
User $75 \mathrm{~kg}$ & $12.15 \mathrm{Wh}$ & $9.34 \mathrm{Wh} / \mathrm{km}$ & $0.076 \mathrm{Wh} / \mathrm{km} / \mathrm{kg}$ \\
\hline
\end{tabular}

TABLe 5: Optimization model parameters.

\begin{tabular}{lcc}
\hline Symbol & Description & Value \\
\hline$(t)$ & Time interval index, from 7:00-19:00 & {$[1,720]$ min } \\
BCTI & Charging time interval for e-bikes, from 10:00-16:00 & {$[180,540]$ min } \\
$D_{\mathrm{AB}}(t)$ & Passenger demand from A (metro station) to B (CIEMAT) & {$\left[D_{\mathrm{AB}}\right]$} \\
$D_{\mathrm{BA}}(t)$ & Passenger demand from B (CIEMAT) to A (metro station) & {$\left[D_{\mathrm{BA}}\right]$} \\
$A_{\mathrm{EB}} \mathrm{CT}$ & Pickup EV trailer capacity (number of e-bikes which can be transported) \\
$\Delta T_{\mathrm{AB}}{ }_{\mathrm{AEB}}$ & Travel time from A to B on e-bikes \\
$\Delta T_{\mathrm{BA}}{ }_{\mathrm{AEB}}$ & Travel time from B to A on e-bikes \\
$\Delta T_{\mathrm{AB}} \mathrm{K}$ & Travel time from A to B of pickup EV \\
$\Delta T_{\mathrm{BA}} \mathrm{K}$ & Travel time from B to A of pickup EV \\
$\mathrm{NB}_{\mathrm{TOT}}$ & Total number of e-bikes available in the system \\
$\mathrm{NB}_{\mathrm{A} 0}$ & Initial number of e-bikes in the docking station A at 7:00 am \\
$\mathrm{NB}_{\mathrm{B} 0}$ & Initial number of e-bikes located at B at 7:00 am \\
$\mathrm{NK}_{\mathrm{TO}}$ & Total number of pick-up EV available in the system \\
$\mathrm{NK}_{\mathrm{A} 0}$ & Number of pick-up EV located at A at 7:00 am \\
$\mathrm{NK}_{\mathrm{B} 0}$ & Number of pick-up EV located at B at 7:00 am \\
$P_{\mathrm{A}}$ & e-bikes parking slots in A \\
$P_{\mathrm{B}}$ & e-bikes parking slots in B & 25 \\
\hline
\end{tabular}

TABLE 6: Integer variables of the optimization model.

\begin{tabular}{|c|c|c|}
\hline Symbol & Description & Value \\
\hline $\mathrm{nb}_{\mathrm{A}}(t)$ & Number e-bikes at A & $(0, \ldots, 25)$ \\
\hline $\mathrm{nb}_{\mathrm{B}}(t)$ & Number e-bikes at B & $(0, \ldots, 25)$ \\
\hline $\mathrm{Cb}_{\mathrm{AB}}(t)$ & $\begin{array}{l}\text { Number e-bikes on pickup EV } \\
\text { from A to B }\end{array}$ & $(0, \ldots, 5)$ \\
\hline $\mathrm{Cb}_{\mathrm{BA}}(t)$ & $\begin{array}{l}\text { Number e-bikes on pickup EV } \\
\text { from B to A }\end{array}$ & $(0, \ldots, 5)$ \\
\hline $\mathrm{nk}_{\mathrm{A}}(t)$ & Number of pickup EV trailers at A & $(0,1)$ \\
\hline $\mathrm{nk}_{\mathrm{B}}(t)$ & Number of pickup EV trailers at B & $(0,1)$ \\
\hline $\mathrm{dk}_{\mathrm{AB}}(t)$ & $\begin{array}{c}\text { Number of pickup EV trailers traveling } \\
\text { from A to B }\end{array}$ & $(0,1)$ \\
\hline $\mathrm{dk}_{\mathrm{BA}}(t)$ & $\begin{array}{c}\text { Number of pickup EV trailers traveling } \\
\text { from B to A }\end{array}$ & $(0,1)$ \\
\hline $\mathrm{db}_{\mathrm{AB}}(t)$ & Number e-bikes traveling from A to B & $(0, \ldots, 25)$ \\
\hline $\mathrm{db}_{\mathrm{AB}}(t)$ & Number e-bikes traveling from B to A & $(0, \ldots, 25)$ \\
\hline
\end{tabular}

Figure 12 represents the charging process along the day. The EV trailer is charged using a level $1230 \mathrm{~V}-16$ A charging station, absorbing $3.7 \mathrm{kWh}$ during each hour. The rest of available energy generation is used to charge e-bike fleet. It is observed that the EV trailer is charged during the first 5 hours (from 10:00 to 14:00), and when the solar generation falls below $3.7 \mathrm{~kW}$, the remaining generation capacity is only used to charge the e-bike fleet. Although from 16:00 there is still solar generation capacity available, the system interrupts the charging process because the employees are starting to come back home using this mobility system again.To get an idea of the evolution of the state of charge of the electric vehicle battery, we use the state of charge (SOC) metric [21]. Since in our case we decide to idealize the efficiencies of the electric power elements of the system, we use a simplified definition of the SOC function.

$$
\mathrm{SOC}=\frac{\mathrm{Ah}_{\text {int }}-\mathrm{Ah}_{\text {consum }}}{\mathrm{Ah}_{\text {rate }}} .
$$

$\mathrm{Ah}_{\text {int }}$ is the initial battery charging state. $\mathrm{Ah}_{\text {consum }}$ is the consumption of the battery. Ah $h_{\text {rate }}$ is the battery rating.

Figure 13 shows the battery state of charge of the pickup EV along the day. At the beginning of the day, the initial SOC is $33.3 \%$, corresponding to $8 \mathrm{kWh}$. As soon as the employees start to arrive to the underground station in the morning, the pickup EV must tow the e-bikes between both locations, consuming energy. This consumption is observed from 7:00 to 10:00. Once all employees are working, the pickup EV is 
TABLE 7: Energy demanded by the proposed e-bike sharing system (e-bikes plus pick up EV trailer).

\begin{tabular}{lcc}
\hline Description & Value & Units \\
\hline Pickup EV trailer consumption & 0.18 & $\mathrm{kWh} / \mathrm{km}$ \\
Number of trips by EV trailer/day & 56 & \\
Total daily pickup EV trailer consumption & 11.088 & $\mathrm{kWh}$ \\
e-bike consumption & 0.0077 & $\mathrm{kWh} / \mathrm{km}$ \\
Number of trips by e-bikes/day & 190 & \\
Total daily e-bike fleet consumption & 1.607 & $\mathrm{kWh}$ \\
Total daily e-bike sharing system consumption & $\mathbf{1 2 . 7}$ & $\mathrm{kWh}$ \\
\hline
\end{tabular}

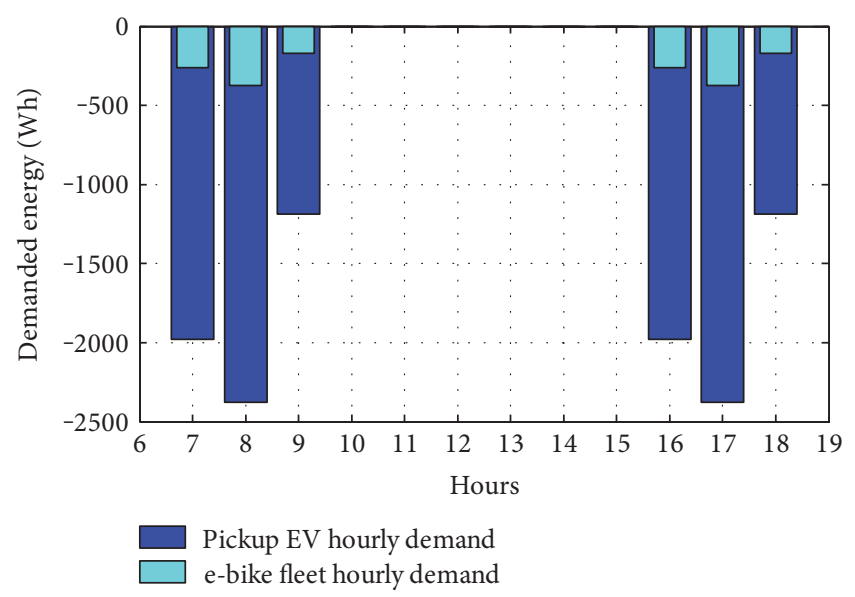

FIGURE 10: e-bike sharing system hourly energy consumption.

charged for 5 hours at CIEMAT building 42. The SOC is linearly increased reaching $87.32 \%(21 \mathrm{kWh})$ at 15:00. During the afternoon, the employees return to their homes, using this e-bike sharing system to reach again the underground station. One more time, the pickup EV will spend energy during this period (until 19:00), reaching a final SOC of $64.22 \%(15.4 \mathrm{kWh})$. This energy will be the initial SOC for the next day, assuming that the battery selfdischarging rate is negligible.

Figure 14 shows the battery state of charge (SOC) of the e-bike fleet along the day. At the beginning of the day, the initial SOC is $11.11 \%$, corresponding to $1 \mathrm{kWh}$. This consumption is observed from 7:00 to 10:00. Once all employees are working, the e-bike fleet is charged for 5 hours at CIEMAT building 42 . The SOC is linearly increased reaching $100 \%$ $(9 \mathrm{kWh})$ at 15:00. During the afternoon, the employees return to their homes, using this e-bike sharing system to reach again the underground station. One more time, the e-bike fleet will spend energy during this period (until 19:00), reaching a final SOC of $91.07 \%(8.2 \mathrm{kWh})$. This energy will be the initial SOC for the next day, assuming that the battery selfdischarging rate is negligible.

\section{Conclusions}

This study concludes that photovoltaics have a huge potential to satisfy the energy demand of mobility systems

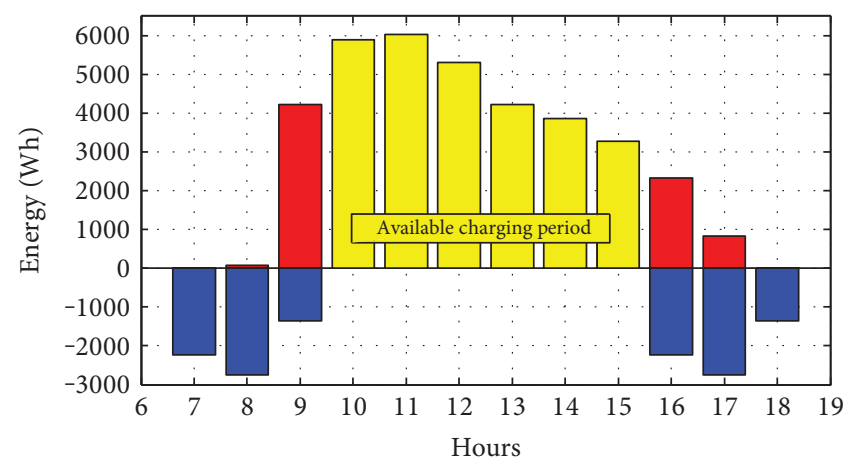

Total e-bike sharing system hourly demand Solar energy hourly estimated generation Solar energy available for charging

FIgURE 11: Total e-bike sharing system energy demand versus solar energy available for charging.
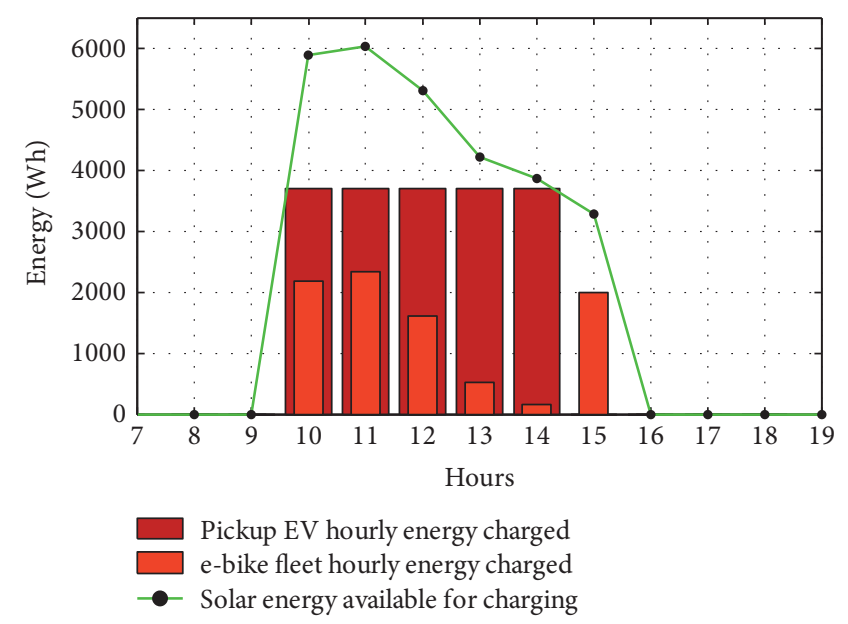

FIGURE 12: Charging process of the e-bike sharing system.

for last-mile employee transportation. The proposed system manages PV energy using only the batteries from the electric vehicles, without requiring any supportive energy storage device.

Taking advantage of the existence of a buildingintegrated PV system currently available at the workplace, we have analyzed and optimized an e-bike sharing system fully powered by solar energy, providing a zero $\mathrm{CO}_{2}$ emission and zero grid electricity consumption system. To determine the total daily electric demand of the e-bike sharing system, different tests were performed over real e-bike models, evaluating the e-bike consumption under several conditions. From the daily mobility requirements of several employees (traveling from the nearest public underground station to their common workplace), an optimization model was designed to size this e-bike sharing system, determining the optimal number of e-bikes and the minimum number of trips required by the pickup EV to keep the balance of e-bikes in both dock stations. In addition, the pickup EV consumption was estimated based on real consumption information. 


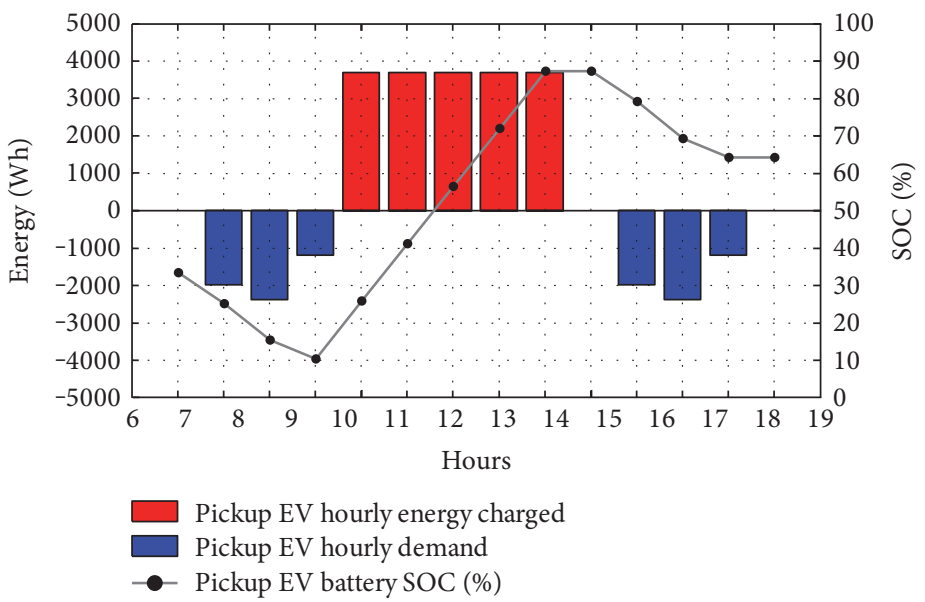

FIGURE 13: EV charging and discharging process and SOC evolution.

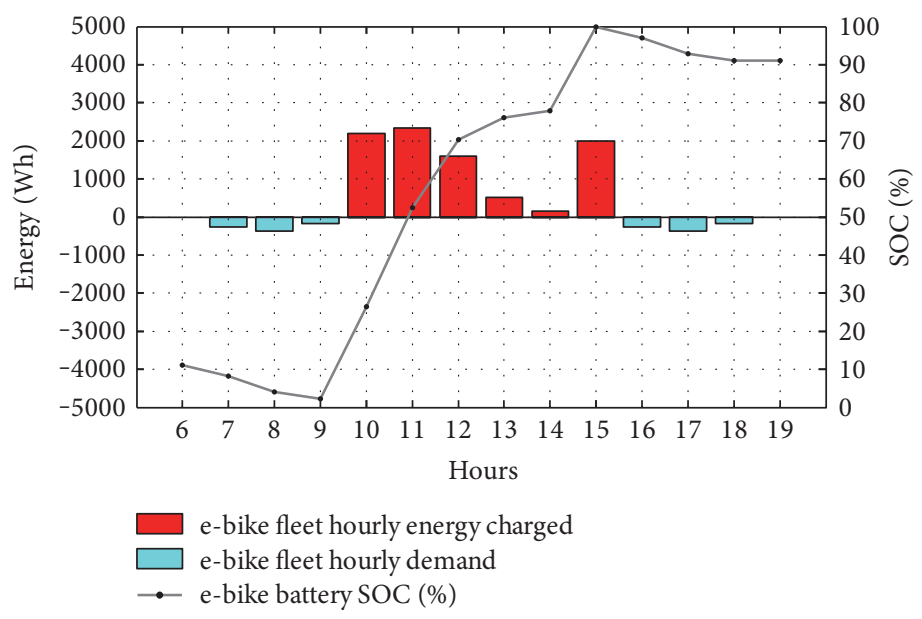

FIGURE 14: e-bike charging and discharging process and SOC evolution.

Related to PV generation, monthly and daily PV electricity production was estimated based on accurate solar radiation data, tilt and orientation data of the PV modules installed in each facade, and the inverter and solar module datasheets.

With all this information, it has been demonstrated that it is completely feasible to design a zero-emission e-bike sharing system to solve the last-mile problem, completing the public transport system. This healthy solution will also allow reducing the GHG emissions in urban areas.

\section{Conflicts of Interest}

The authors declare that they have no competing interests.

\section{Acknowledgments}

The research leading to these results has received funding from the European Union Seventh Framework Programme (FP7/2007-2013) under Grant Agreement no. 270833.

\section{References}

[1] EU, "Directive 2009/29/EC of the European Parliament and of the Council of 23 April 2009 amending directive 2003/87/EC so as to improve and extend the greenhouse gas emission allowance trading scheme of the community," Journal of the European Union, vol. 5, pp. 63-87, 2009.

[2] Q. K. Hassan, K. Mahmud Rahman, A. S. Haque, and A. Ali, "Solar energy modelling over a residential Community in the City of Calgary, Alberta, Canada," International Journal of Photoenergy, vol. 2011, Article ID 216519, p. 8, 2011.

[3] N. M. Chivelet, J. C. G. García, M. A. Abella, and F. C. Romero, "Integration of solar photovoltaic energy into the rehabilitation of CIEMAT building 42," Vértices, vol. 5, no. 25, pp. 28-32, 2016, http://www.ciemat.es/portal .do? IDM=226\&NM=3.

[4] Y. C. Huang, C. C. Chan, S.-C. Kuan, S. J. Wang, and S. K. Lee, "Analysis and monitoring results of a building integrated photovoltaic façade using PV ceramic tiles in Taiwan," International Journal of Photoenergy, vol. 2014, Article ID 615860, p. 12, 2014. 
[5] Y. J. Chiu and T. M. Ying, "A novel method for technology forecasting and developing R\&D strategy of building integrated photovoltaic technology industry," Mathematical Problems in Engineering, Article ID 273530, p. 24, 2012.

[6] UN-Habitat, State of the World's Cities 2012/2013, 2016, https://sustainabledevelopment.un.org/content/documents/74 5habitat.pdf.

[7] M. Fuentes, Impact of Energetic Management on the Development of LEVS as a Mode Alternative Transport Solutions Mobility to Urban/Metropolitan, Technical Report CIEMAT, p. 126, 2011.

[8] K. Martens, "The bicycle as a feedering mode: experiences from three European countries," Transportation Research Part D: Transport and Environment, vol. 9, no. 4, pp. 281-294, 2004.

[9] S. Shaheen, S. Guzman, and H. Zhang, "Bikesharing in Europe, the Americas, and Asia: past, present, and future," Transportation Research Record: Journal of the Transportation Research Board, vol. 2143, pp. 159-167, 2010.

[10] P. DeMaio, "Bike-sharing: history, impacts, models of provision, and future," Journal of Public Transportation, vol. 12, no. 4, p. 3, 2009.

[11] H. Sayarshad, S. Tavassoli, and F. Zhao, "A multi-periodic optimization formulation for bike planning and bike utilization," Applied Mathematical Modelling, vol. 36, no. 10, pp. 4944-4951, 2012.

[12] P. Lebeau, C. De Cauwer, J. VanMierlo, C. Macharis, W. Verbeke, and T. Coosemans, "Conventional, hybrid, or electric vehicles: which technology for an urban distribution centre?" The Scientific World Journal, vol. 2015, Article ID 302867, p. 11, 2015.

[13] S. Ji, C. R. Cherry, L. D. Han, and D. A. Jordan, "Electric bike sharing: simulation of user demand and system availability," Journal of Cleaner Production, vol. 85, pp. 250-257, 2014.

[14] E. Blasius, E. Federau, P. Janik, and Z. Leonowicz, "Heuristic storage system sizing for optimal operation of electric vehicles powered by photovoltaic charging station," International Journal of Photoenergy, vol. 2016, Article ID 7134904, p. 12, 2016.

[15] Campus Moncloa, Campus of International Excellence MONCLOA, 2016, http://www.campusmoncloa.es/en/campus-mon cloa/welcome.php.

[16] Joint Reseach Center, EU, "Photovoltaic geographical information system - interactive maps," 2016, http://re.jrc.ec.europa.eu/ pvgis/apps4/pvest.php.

[17] J. Jurasz and J. Mikulik, "Investigating theoretical PV energy generation patterns with their relation to the power load curve in Poland," International Journal of Photoenergy, vol. 2016, Article ID 3789840, p. 7, 2016.

[18] Cycling London, Cycle Mph Average Speed in London, 2016, http://cycling-london.blogspot.com.es/2006/04/cyclemph-average-speed-in-london.html.

[19] Nissan, E-nv200. Range and Specifications, 2016, https:// www.nissan.co.uk/vehicles/new-vehicles/e-nv200/chargingrange.html.

[20] M. Thwaite, Review: 2014 Nissan e-NV200 Electric Van, 2016, https://transportevolved.com/2015/04/18/2014-nissane-nv200-review/.

[21] B. G. Yu, "Design and experimental results of battery charging system for microgrid system," International Journal of Photoenergy, vol. 2016, Article ID 7134904, p. 6, 2016. 

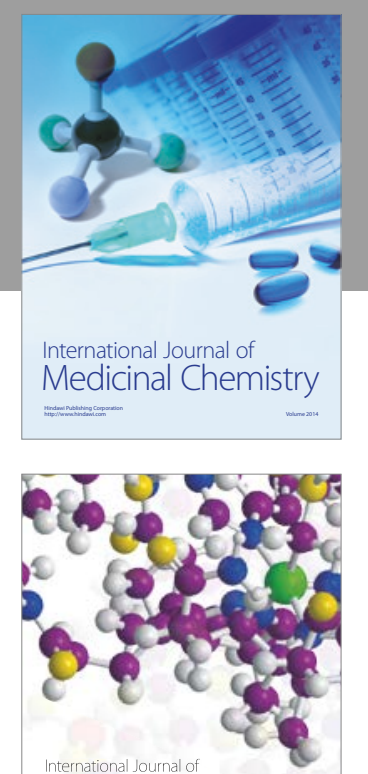

Carbohydrate Chemistry

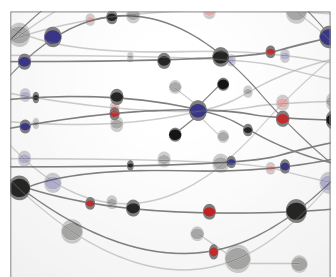

The Scientific World Journal
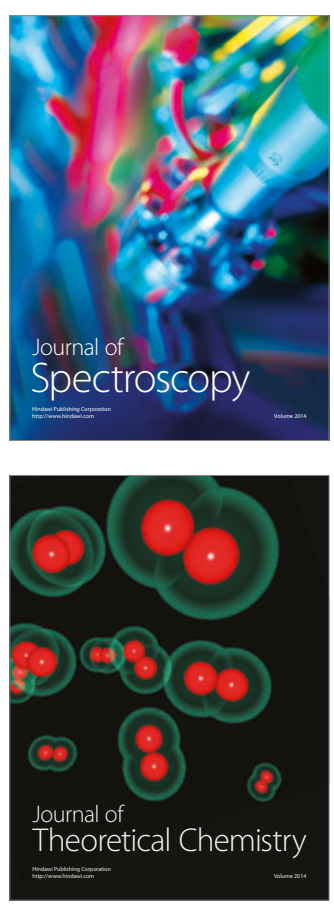
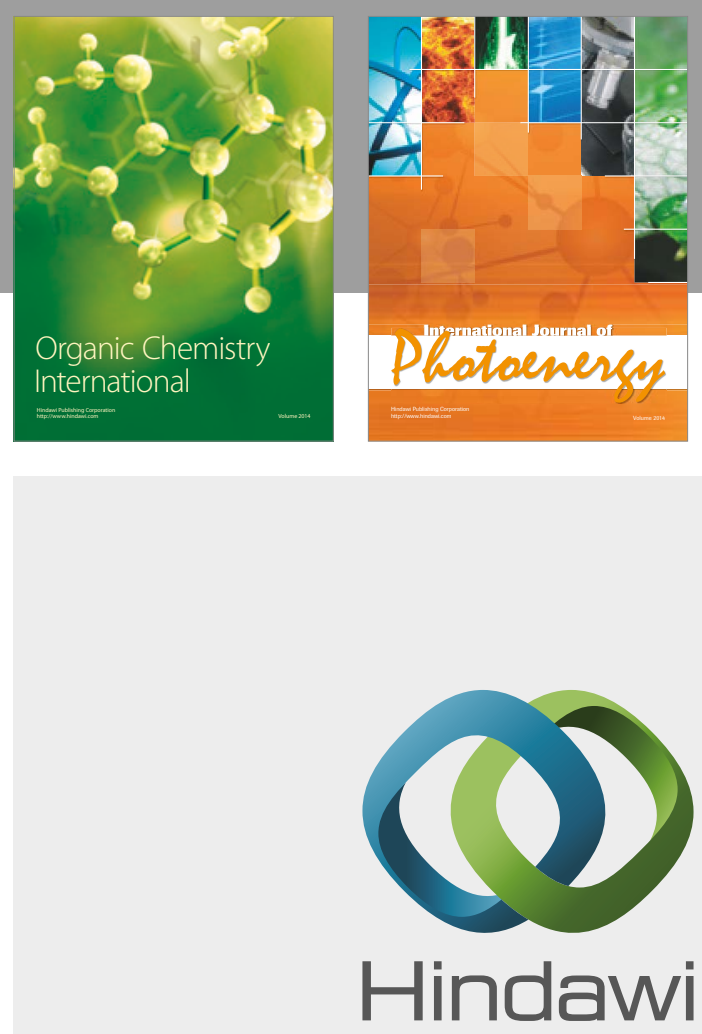

Submit your manuscripts at

https://www.hindawi.com

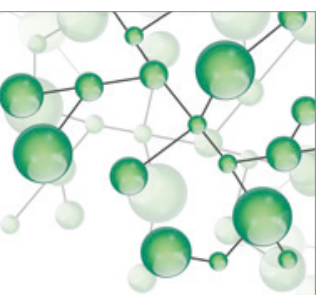

International Journal of

Inorganic Chemistry

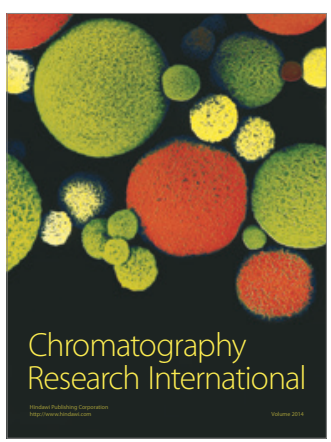

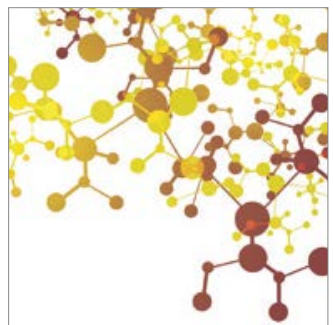

Applied Chemistry
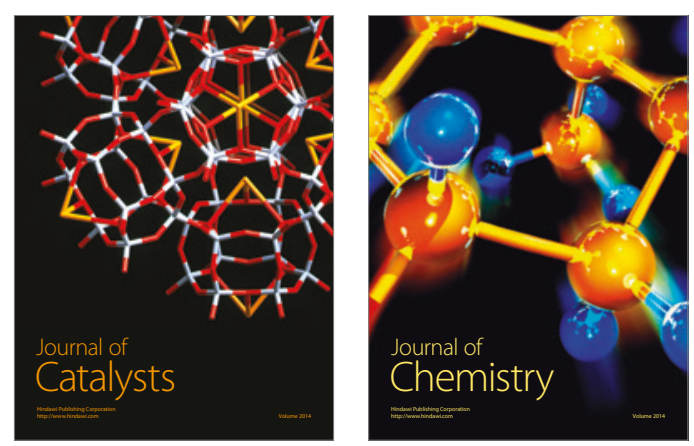
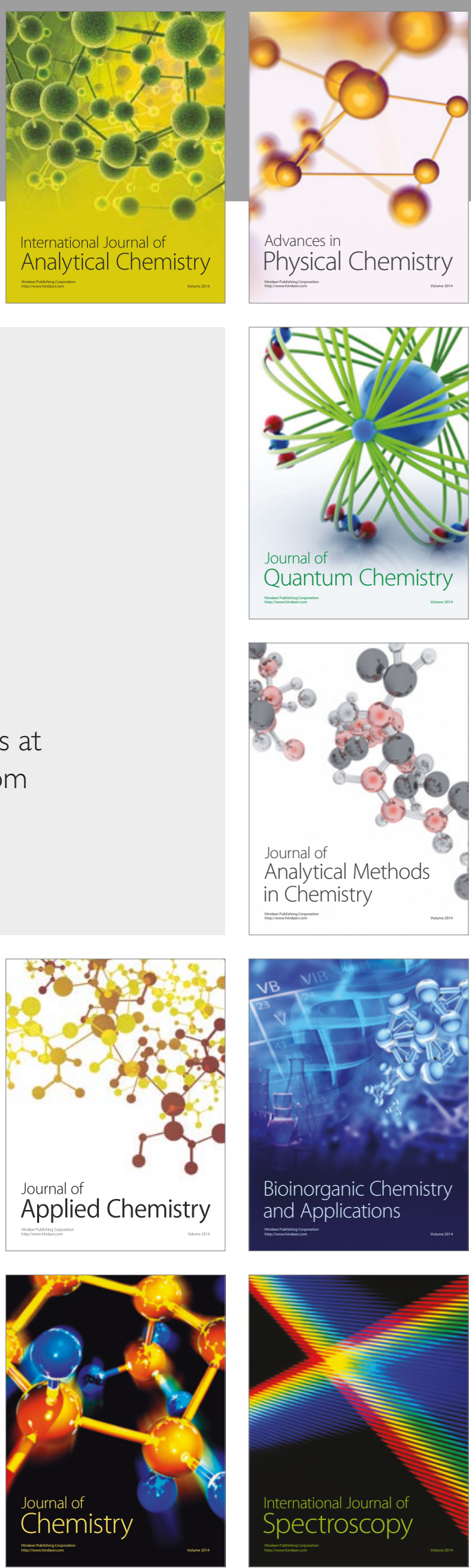